\title{
RANCANG BANGUN APLIKASI PEMBELAJARAN RAMBU-RAMBU LALU LINTAS DAN MARKA JALAN UNTUK PENINGKATAN KESADARAN BERLALU LINTAS
}

\author{
${ }^{1}$ Fira Leisyalika, ${ }^{2}$ Dhian Nur Rahayu \\ E-mail : ${ }^{1}$ leisyalikafira@gmail.com, ${ }^{2}$ dhian@dosen.rosma.ac.id
}

\begin{abstract}
ABSTRAK
Dibeberapa wilayah seperti dibeberapa lampu lalu lintas sering sekali banyak pengguna jalan melakukan pelanggaran, seperti tetap menjalankan kendaraan walaupun lampu rambu-rambu lalu lintas sedang menyala merah, lampu rambu-rambu lalu lintas belum menyala hijau tetapi sudah jalan, berhenti di zebra cross atau sengaja melewati zebra cross, dan melewati batas marka jalan. Hal ini terjadi karena kurangnya pengetahuan dari pengguna jalan terhadap aturan rambu-rambu lalu lintas. Ketertiban adminstrasi berkendara, pemilik kendaraan wajib memiliki Surat Tanda Nomor Kendaraan (STNK) dan Surat Izin Mengemudi (SIM) yang diterbitkan langsung oleh pihak terkait. Pelanggaran berlalu lintas juga cukup banyak terjadi pada pengendara yang belum memiliki Surat Izin Mengemudi. Hal tersebut terjadi karena kegagalan dalam melakukan tes tertulis yang berisi soalsoal tentang rambu-rambu lalu lintas dan marka jalan pada saat mengajukan pembuatan Surat Izin Mengemudi. Diperlukan suatu edukasi agar masyarakat mengetahui dan belajar tentang ramburambu lalu lintas dan marka jalan dengan cara dibuat suatu media pembelajaran berupa aplikasi multimedia berbasis android tentang pembelajaran rambu-rambu lalu lintas beserta marka jalannya.
\end{abstract}

Kata Kunci: Rambu-rambu, Marka Jalan, Multimedia, Android.

\begin{abstract}
In some areas, such as some traffic lights, many road users often commit violations, such as continuing to run a vehicle even though the traffic lights are red, traffic lights have not turned green, but they are already running, stop on zebra crossing or accidentally pass zebra crossing, and crossing the road mark. This happens because of the lack of knowledge from road users of traffic rules. In the driving order of the administration, the vehicle owner must have a Vehicle Number (STNK) and Driving License (SIM) issued directly by the related part. Traffic violations also occur quite a lot for motorists who do not have a driver's license. This happens because of a failure in carrying out a writing test that contains questions about traffic signs and road markings when submitting a Driving License. An education is needed so that people know and learn about traffic signs and road markings by creating a learning media in the form of android-based multimedia applications about learning traffic signs along with road markings.
\end{abstract}

Keywords: Signs, Road Markings, Multimedia, Android. 


\section{Pendahuluan}

Menurut data sensus dari Badan Pusat Statistik Kabupaten Karawang, jumlah kendaraan sejenis Sedan, Jeep, Minibus, dan sejenisnya ada sebanyak 57.369, sepeda motor roda 2 dan 3 ada sebanyak 750.552. (Sumber data: BPS kabupaten Karawang tahun 2017). Jumlah kendaraan ini adalah kendaraan yang dimiliki oleh Dinas Pemerintahan maupun pribadi. Hal ini terlihat ketika pagi sebelum jam kerja ataupun pada sore hari setelah jam pulang pekerja di beberapa wilayah terjadi kepadatan dan kemacetan kendaraan di beberapa titik, diantaranya yaitu di pertigaan Pasar Kosambi, perempatan Kopel Karawang, lampu merah Klari, dan terminal Klari.

Adminstrasi tertib dalam berkendara ini, pemilik kendaraan wajib memiliki STNK (Surat Tanda Nomor Kendaraan) dan SIM (Surat Izin Mengemudi) yang diterbitkan langsung oleh pihak terkait. Selain itu pengendara wajib memakai helm bagi pengendara roda dua dan memakai sabuk pengaman/safety belt bagi pengendara roda empat, serta pengendara wajib mentaati rambu-rambu lalu lintas yang ada di sepanjang jalan, juga memahami marka jalan yang ada. Hal ini diharapkan dapat menghindari terjadinya pelanggaran berlalu lintas dan terhindar dari kecelakaan lalu lintas, sehingga menciptakan tertib berlalu lintas.

Berdasarkan dari data yang dirilis oleh pihak Kepolisian Polres Karawang, bahwa korban meninggal akibat kecelakaan lalu lintas dari tahun 2016 sampai dengan tahun 2017, mengalami peningkatan. Pada tahun 2016: korban meninggal akibat kecelakaan lalu lintas sebanyak 65 orang dan luka berat ada 287 orang, serta luka ringan 454 orang. Data tahun 2017: korban meninggal ada 103 orang, luka berat ada 217 orang dan luka ringan ada 103 orang. (Sumber data: Polres kabupaten Karawang). Ini berarti ada peningkatan angka kecelakaan karena banyaknya faktor-faktor yang menyebabkan terjadinya kecelakaan.

Dibeberapa wilayah seperti dibeberapa lampu merah sering sekali banyak pengguna jalan melakukan pelanggaran, seperti tetap menjalankan kendaraan walaupun lampu ramburambu lalu lintas sedang menyala merah, lampu rambu-rambu lalu lintas belum menyala hijau tetapi sudah jalan, berhenti di zebra cross atau sengaja melewati zebra cross, dan melewati batas marka jalan. Hal ini terjadi karena kurangnya pengetahuan dari pengguna jalan terhadap aturan rambu-rambu lalu lintas.

Selain itu, pelanggaran berlalu lintas yang cukup banyak yaitu pengendara yang belum memiliki Surat Izin Mengemudi (SIM). Hal tersebut terjadi karena kegagalan dalam melakukan tes tertulis yeng berisi soal-soal tentang rambu-rambu lalu lintas dan mraka jalan pada saat mengajukan pembuatan SIM. Faktor penyebab kegagalan dalam pelaksanaan tes tertulis soal-soal tentang rambu-rambu lalu lintas salah satunya karena tidak paham terhadap arti dari rambu-rambu lalu lintas dan marka jalan yang ada. Berdasarkan permasalahan tersebut, diperlukan suatu edukasi agar masyarakat mengetahui dan belajar tentang rambu-rambu lalu lintas dan marka jalan, salah satunya yaitu membuat suatu media pembelajaran berupa aplikasi.

Menindak lanjuti dari permasalahan tersebut, maka peneliti tertarik untuk membuat sebuah aplikasi mulitimedia berbasis android tentang pembelajaran rambu-rambu lalu lintas dan marka jalan dengan mengacu pada UndangUndang Nomor 22 Tahun 2009 dan Peraturan Menteri Perhubungan Republik Indonesia Nomor PM 34 Tahun 2014, tentang Lalu Lintas dan Angkutan Jalan dengan judul "Rancang Bangun Aplikasi Pembelajaran Rambu-Rambu Lalu Lintas dan Marka Jalan Untuk Peningkatan Kesadaran Berlalu Lintas".

\section{Metodologi Penelitian}

Peneliti di dalam memperoleh data sebagai bahan penulisan penelitian dan pembahasan masalah, penulis menggunakan metode kualitatif action research. Berikut ini adalah gambaran dari metode kualitatif action research:

1. Menentukan topik, yaitu langkah pertama yang harus ditetapkan pertama kali dalam menyusun langkah-langkah penelitian. Dalam hal ini penulis akan membuat topik penelitian tentang pembelajaran rambu- 
rambu lalu lintas dan marka jalan berbasis andoid.

2. Identifikasi masalah, merupakan salah satu hal yang sangat penting dalam pembuatan penelitian, karena dengan adanya identifikasi masalah ini yang berarti mengkaji dan mempelajari tentang permasalahan yang akan diangkat dalam pembuatan penelitian. Dalam hal ini penulis mengidentifikasikan masalahnya yaitu bagaimana merancang aplikasi untuk meningkatkan kesadaran berlalu lintas.

3. Menentukan judul, pada dasarnya dalam menentukan judul harus jelas dan spesifik. Konsep-konsep utama harus dimasukan. Variabel-variabel yang akan diselidiki harus masuk pada judul penelitian. Dalam hal ini berdasarkan hasil identifikasi masalah yang ada, judul yang akan dibuat adalah rancang bangun aplikasi pembelajaran rambu-rambu lalu lintas untuk peningkatan kesadaran berlalu lintas (Studi kasus: Polres Karawang).

4. Pengumpulan data, merupakan langkah yang paling strategis dalam penelitian, karena tujuan utama dari penelitian adalah mendapatkan data. Dalam hal pengumpulan data, terbagi kedalam beberapa tahapan yaitu wawancara, observasi, studi literatur dan kuisioner.

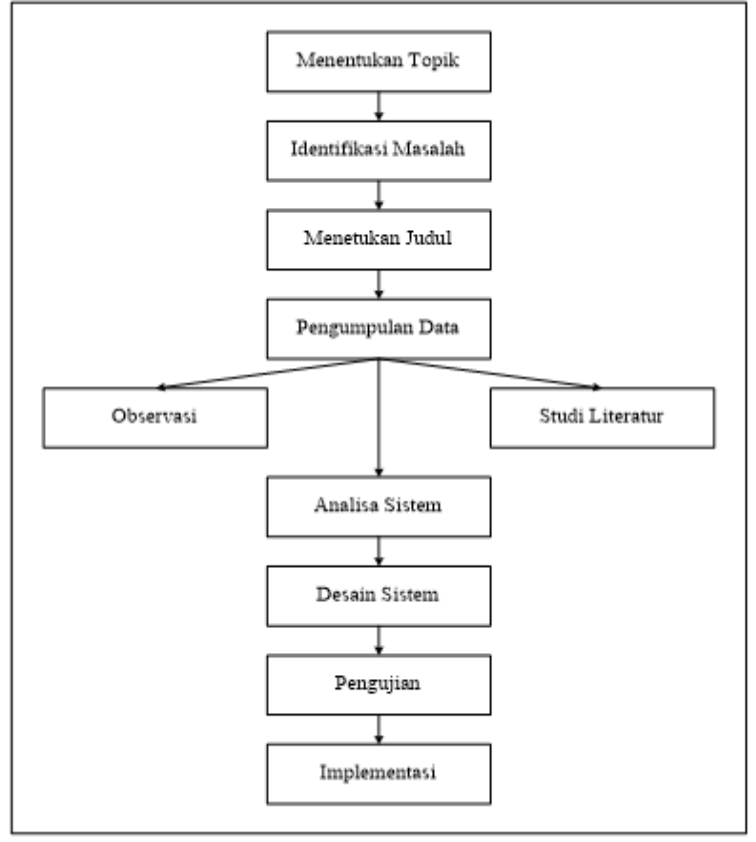

Gambar 1. Metode kualitatif Action Research
5. Observasi, merupakan suatu proses yang kompleks, suatu proses yang tersusun dari berbagai proses biologis dan psikologis. Observasi yang dilakukan penulis di Unit Dikyasa (Pendidikan Rekayasa Lalu Lintas) Lantas Polres Karawang.

6. Studi literatur, adalah mencari referensi teori yang relevan dengan kasus atau permasalahan yang ditemukan.

7. Analisa sistem, merupakan sebuah metode untuk mencari solusi dari permasalahan sistem yang ada dengan cara mengelompokkan komponen yang ada menjadi komponen-komponen yang lebih kecil agar solusi yang ditemukan sesuai dengan kebutuhan sistem.

8. Desain sistem, dalam hal ini untuk memudahkan dalam pemahaman terhadap sistem yang akan dibuat, maka penulis akan membuatnya dalam bentuk pemodelan sistem UML.

9. Pengujian, dalam hal ini untuk mengecek hasil dari sistem yang telah dibuat, penulis melakukan pengecekan dengan metode black box.

10.Implementasi, dalam hal ini penulis akan membagikan file.apk yang dihasilkan dari android studio kepada pengguna jalan.

\section{Tinjauan Pustaka}

\section{Pengertian Aplikasi Android}

Menurut Ali Zaki dan Smitdev Community (2011:7), “aplikasi adalah komponen yang berguna melakukan pengolahan data maupun kegiatan-kegiatan seperti pembuatan dokumen atau pengolahan data.

Menurut Nazruddin Safaat H. (2015:18), "andorid adalah sebuah sistem operasi untuk perangkat mobile berbasis Linux yang mencangkup sistem operasi, middleware, dan aplikasi”.

Menurut Nazaruddin Safaat H. (2011:9), "aplikasi android ditulis dalam bahasa pemrogramman java. Kode java dikompilasikan bersama dengan data file resource yang dibutuhkan oleh aplikasi, dimana prosesnya dipackage oleh tools yang dinamakan "apt tools" ke dalam paket android sehingga menghasilkan 
file dengan ekstensi apk. File apk itulah yang kita sebut dengan aplikasi, dan nantinya dapat diinstall di perangkat mobile".

Ada empat komponen penting pada aplikasi android, yaitu:

1. Activity, Suatu activity akan menyajikan user interface kepada pengguna, sehingga pengguna dapat melakukan interaksi.

2. Service, Service tidak memiliki Graphic User Interface (GUI), tetapi service berjalan secara background, sebagai contoh dalam memainkan musik,

3. Broadcast Receiver, berfungsi menerima dan bereaksi untuk menyampaikan notifikasi.

4. Content Provider, membuat kumpulan aplikasi data secara spesifik sehingga bisa digunakan oleh aplikasi lain.

Menurut Robin dan Linda (Benardo, 2011), "multimedia interaktif adalah alat yang dapat menciptakan persentasi yang dinamis dan interaktif, yang mengkombinasikan teks, grafik, animasi, audio dan gambar video".

Berdasarkan Undang-Undang Republik Indonesia Nomor 22 Tahun 2009 Tentang Lalu Lintas dan Angkutan Jalan, Pasal 1 Ayat 1 arti dari Lalu Lintas dan Angkutan Jalan adalah satu kesatuan sistem yang terdiri atas Lalu Lintas, Angkutan Jalan, Jaringan Lalu Lintas dan Angkutan Jalan, Prasarana Lalu Lintas dan Angkutan Jalan, Kendaraan, Pengemudi, Pengguna Jalan, serta pengelolaannya.

Spesifikasi Teknis Rambu Lalu Lintas diatur dalam Peraturan Menteri Perhubungan Republik Indonesia Nomor PM 34 Tahun 2014 Bagian kesatu umum mulai pasal 3.

Rambu Lalu Lintas berdasarkan jenisnya terdiri atas:
a. rambu peringatan;
b. rambu larangan;
c. rambu perintah; dan
d. rambu petunjuk.

\section{Metode Penelitian}

Penelitian ini menggunakan metode pengumpulan data dan metode pengembangan aplikasi.
1. Metode Pengumpulan Data

Dalam penelitian ini Penulis menggunakan teknik pengumpulan data observasi dan studi literatur. Metode pengamatan ini dilakukan peninjauan dan penelitian langsung di lapangan untuk memperoleh dan mengumpulkan data yang dibutuhkan.

2. Metode Pengembangan Aplikasi

Metode pengembangan sistem yang digunakan yaitu metode kualitatif action research, dengan urutan langkah sebagai berikut:

a. Menentukan Topik

Pada penelitian ini topik yang diambil adalah membuat suatu aplikasi rambu-rambu lalu lintas dan marka jalan berbasis android.

e. Identifikasi Masalah

Dalam tahap ini mengidentifikasikan masalah mengenai pemahaman mengenai pengetahuan tentang rambu-rambu lalu lintas dan marka jalan, menginformasikan kepada masyarakat arti dari rambu-rambu lalu lintas dan marka jalan agar dapat meningkatkan kesadaran berlalu lintas.

f. Menentukan Judul

Dalam menentukan judul diambil dari variabel-variabel yang teliti yaitu pembelajaran rambu-rambu lalu lintas dan marka jalan yang dibuat dengan media aplikasi berbasis android.

g. Pengumpulan Data

Data diambil dari informasi mengenai arti dari rambu-rambu lalu lintas dan marka jalan dengan cara observasi dan studi literatur.

h. Analisis Aplikasi

Berikut adalah gambar flowchart untuk halaman utama, dimana saat User membuka aplikasi akan muncul menu kulai dan Keluar. Jika User memilih menu mulai maka akan muncul beberapa menu yaitu: menu tutorial, menu simulasi soal, menu petunjuk, dan menu keluar. Jika User memilih menu keluar maka akan menutup aplikasi: 


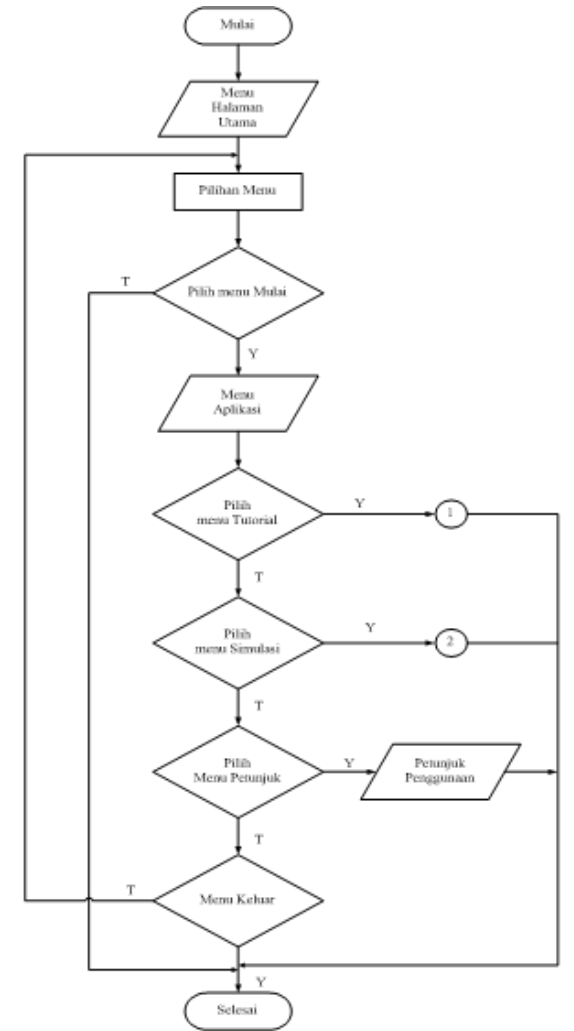

Gambar 2 Flowchart Tampilan Home

Kemudian di bawah ini adalah gambar flowchart untuk menu tutorial dimana saat User memilih menu tutorial akan muncul tampilan beberapa menu, yaitu: menu rambu lalu lintas, menu rambu larangan, menu rambu petunjuk, menu marka jalan, dan menu ke menu sebelumnya.

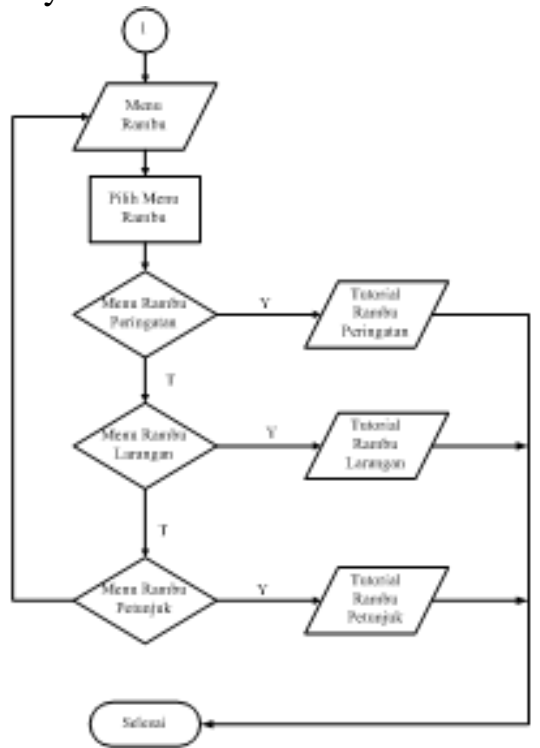

Gambar 3. Flowchart Menu Tutorial
Gambar 4 adalah flowchart untuk menu simulasi soal, yaitu sebuah menu yang digunakan untuk menguji User mengenai sejauh mana pengetahuan User terhadap rambu-rambu lalu lintas dan marka jalan. Jika User memilih menu Simulasi Soal maka akan muncul soal pertanyaan yang harus dijawab oleh User. Setelah User menjawab pertanyaan tersebut maka akan diproses untuk dikoreksi dan mengetahui hasil jawaban dari User.

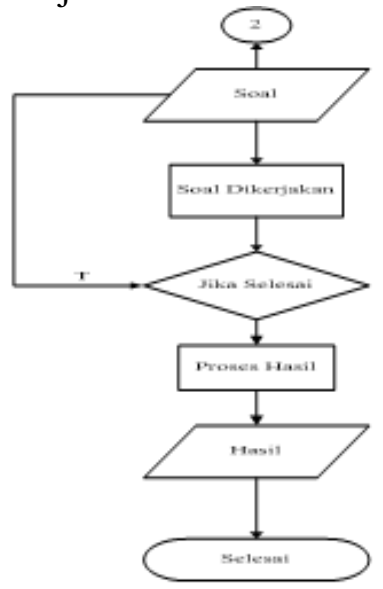

Gambar 4. Flowhart Simulasi Soal

Berikut ini adalah algoritma dari simulasi soal rambu-rambu lalu lintas dan marka jalan, yaitu:

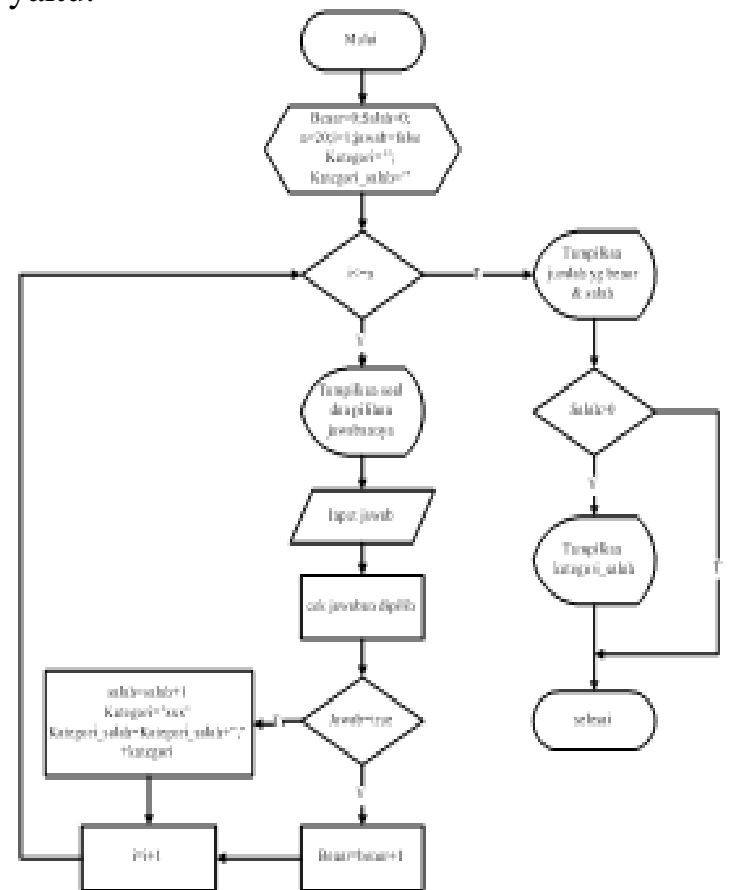

Gambar 5. Flowchart Algoritma Simulasi Soal 
Gambar 5 dapat dijelaskan bahwa ketika mulai maka akan diikuti dengan persiapan variable: benar, salah, kategori, kategori_salah, i dan $n$. Kemudian akan ada pengecekan nilai I, apakah nilai $\mathrm{i}<=\mathrm{n}$, jika iya maka akan menampilkan soal rambu-rambu lalu lintas dan marka jalan yang berupa gambar tertentu, selain itu juga akan menampilkan pilihan jawaban dari gambar tersebut. Setelah itu akan ada penerimaan inputan jawaban dari soal yang diberikan, selanjutnya akan dilakukan pengecekan terhadap kebenaran pilihan jawaban tersebut. Jika pilihan jawaban adalah benar maka jumlah yang benar akan bertambah 1 , sebaliknya jika jawaban adalah salah, maka jumlah salah akan bertambah 1 .

Setelah itu maka akan terjadi penambahan nilai terhadap variable i. Selanjutnya akan terjadi pengecekan nilai variable i kembali, yaitu apakah nilai $\mathrm{i}<=\mathrm{n}$, jika salah maka akan dilakukan instruksi seperti dijelaskan pada kalimat-kalimat sebelumnya, sedangkan jika iya maka akan menampilkan jumlah yang benar dan salah berapa. Setelah itu selesai.

i. Desain Aplikasi

Untuk memudahkan dalam pemahaman terhadap sistem yang akan dibuat, maka penulis akan membuatnya dalam bentuk pemodelan sistem UML.

\section{Desain Use Case}

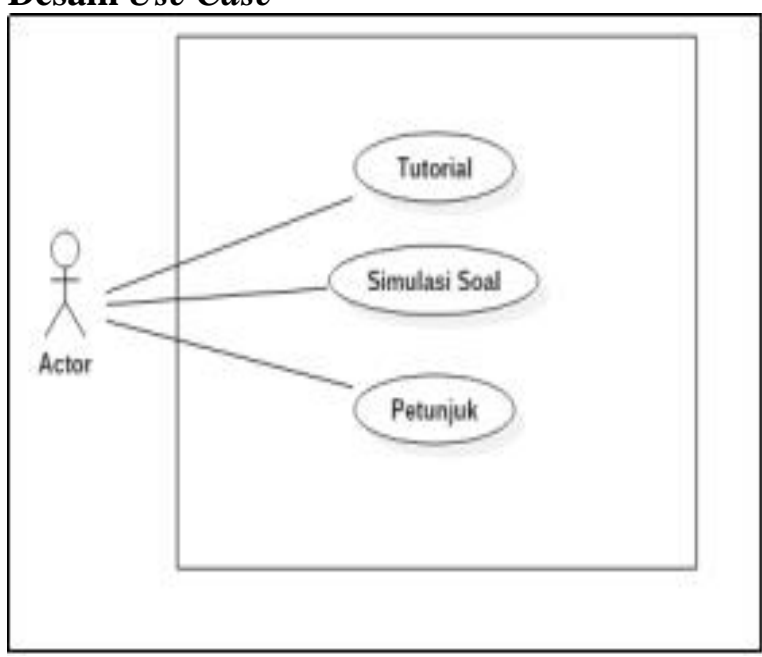

Gambar 6 Desain Use Case

\section{Desain Activity Diagram}

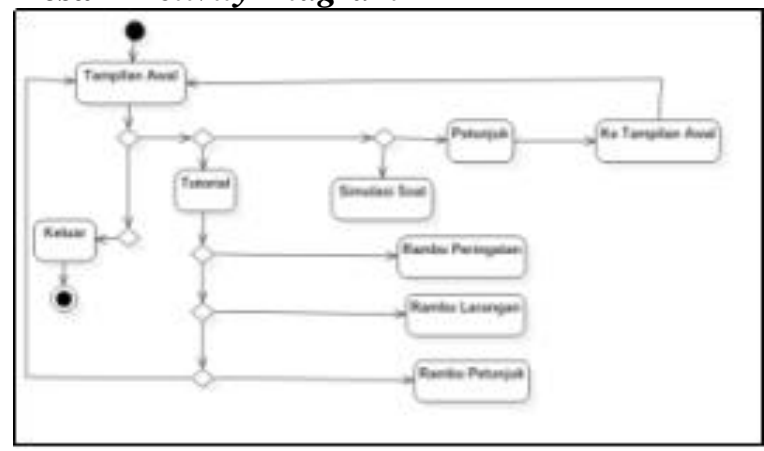

Gambar 7 Desain Activity Diagram

Tampilan awal terdapat menu mulai yang mana User akan memilih menu yang akan User buka, diantaranya ada beberapa menu, yaitu:

1. Tutorial soal, di dalamnya User dapat melihat beberapa menu yang terdiri dari menu rambu peringatan, menu rambu larangan, menu rambu petunjuk, menu marka jalan, dan menu ke menu sebelumnya.

2. Simulasi soal, User harus menjawab beberapa soal yang ditampilkan.

3. Petunjuk, di dalamnya User dapat melihat petunjuk aplikasi.

4. Keluar, menu yang dapat membuat User keluar ke tampilan awal aplikasi.

\section{Desain Sequence Diagram}

Desain Sequence Diagram ini menggambarkan arus pekerjaan atau informasi pesan dari aktor ke sistem atau sebaliknya. Berikut ini adalah sequence diagram ramburambu lalu lintas dan marka jalan yang oleh Penulis digambarkan dalam empat penjabaran, yaitu:

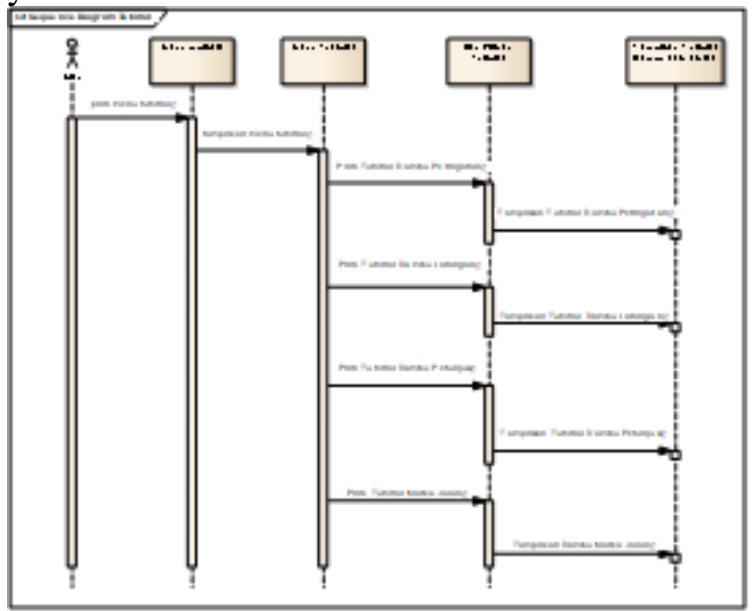

Gambar 8 Sequence Diagram Tutorial 
Dari gambar 8 dapat dijelaskan ketika User memilih menu tutorial, maka akan tampil 4 pilihan, yaitu pilihan tutorial rambu peringatan, tutorial rambu larangan, tutorial rambu petunjuk, dan tutorial marka jalan. Ketika memilih salah satu pilihan tutorial, maka akan tampil menu tutorial sesuai dengan yang dipilih.

\section{Sequence Diagram Petunjuk}

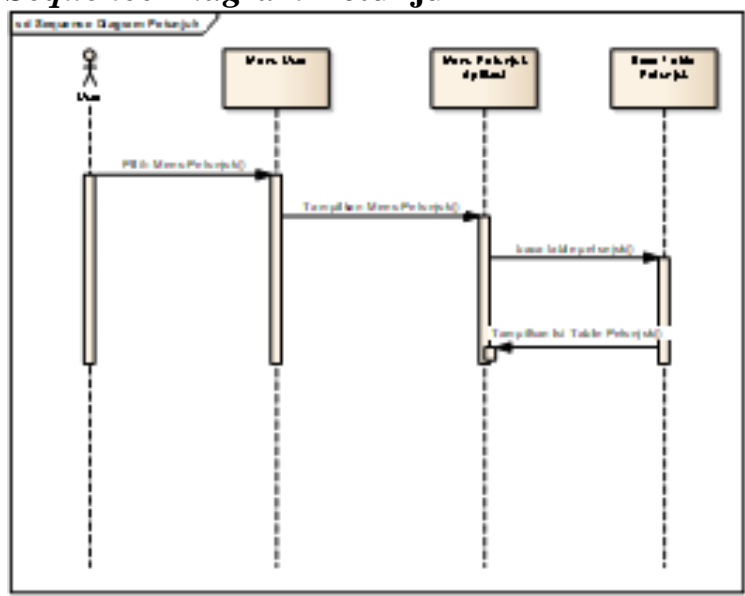

Gambar 9 Sequence Diagram Tutorial

Gambar 9 menjelaskan ketika User memilih menu petunjuk, maka sistem akan membaca isi dari table petunjuk, kemudian akan menampilkan isi datanya ke menu petunjuk.

\section{Sequence Diagram Simulasi Soal}

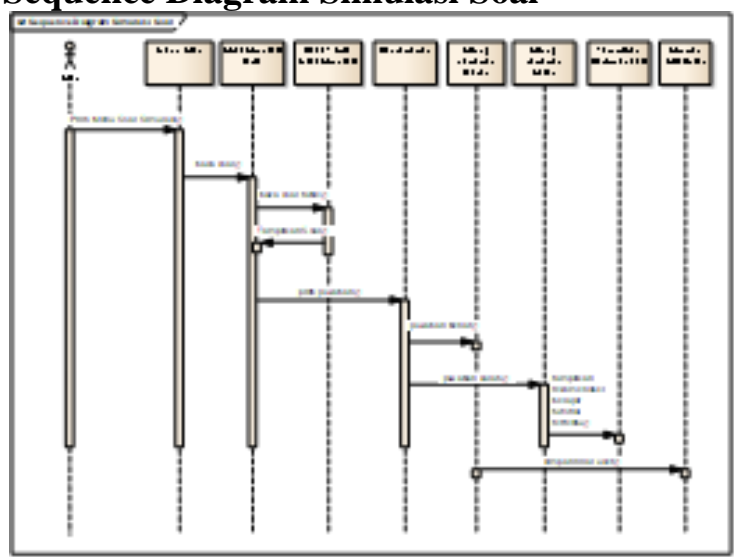

Gambar 10. Sequence Diagram Simulasi Soal

Gambar 10 menjelaskan ketika User memlilih menu soal simulasi, maka sistem akan membaca soal-soal yang ada di table dan akan ditampilkan ke layar agar dapat dibaca oleh User dan menampilkan juga pilihan jawabannya.
Ketika User memilih salah satu jawaban, maka sistem akan mengecek jawaban tersebut apakah benar atau salah.

\section{j. Pengujian}

Pendekatan yang dilakukan dalam pengujian aplikasi ini yaitu menggunakan pendekatan black-box testing. Pendekatan ini melakukan pengujian dengan memfokuskan pada kebutuhan dari software/perangkat lunak.

\section{k. Implementasi}

Implementasi menjelaskan penerapan aplikasi berbasis android ini dengan menggunakan Android Studio.

\section{Rancangan Perangkat Lunak}

Perangkat lunak yang digunakan dalam perancangan aplikasi ini adalah Windows 10 (operating sistem yang digunakan), Android Studio (aplikasi yang digunakan untuk membuat game), dan Droid4X (emulator android yang digunakan).

\section{Rancang Bangun}

Untuk memudahkan dalam pembuatan aplikasi rambu-rambu lalu lintas dan marka jalan berbasis android, maka Penulis merancangkan sketsa dari aplikasi yang akan dibangun yaitu sebagai berikut:

a. Rancang Tampilan Awal Aplikasi

\section{Aplikasi Rambu-rambu Lalu Lintas} Dan Marka Jalan
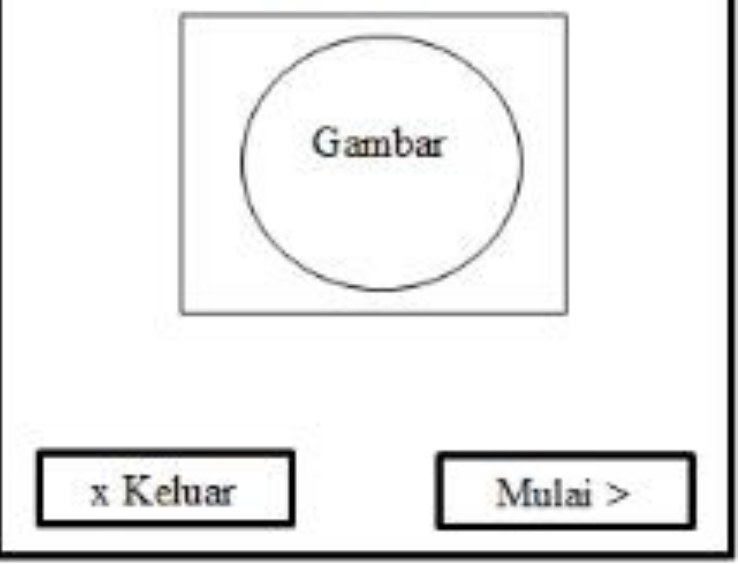

Gambar 11 Rancangan Awal Aplikasi 
Gambar 11 merupakan tampilan awal aplikasi, untuk melanjutkan ke aplikasi ini dapat dengan memilih menu mulai, sedangkan untuk keluar dari aplikasi ini adalah dengan memilih menu keluar.

b. Rancang Tampilan Menu Home Aplikasi

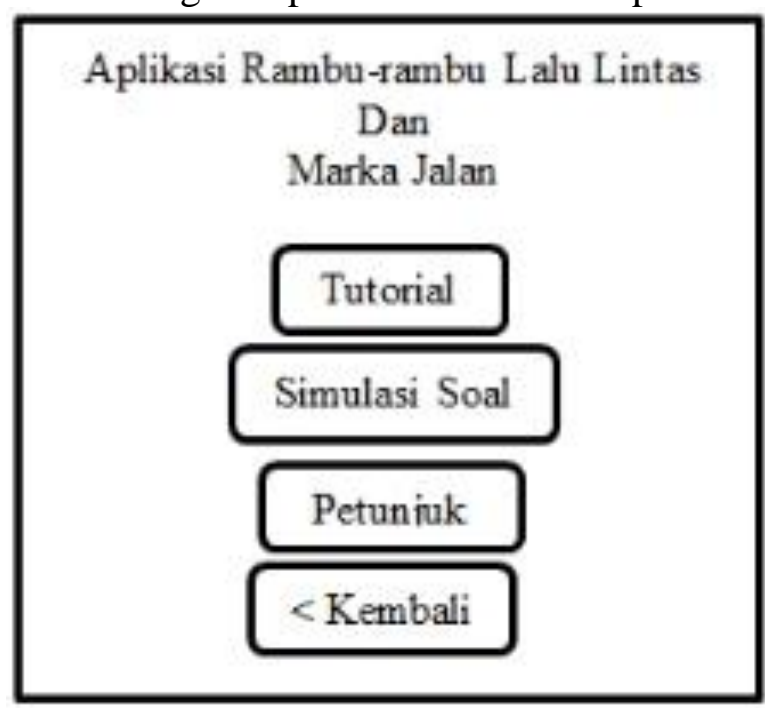

Gambar 12 Rancangan Menu Home Aplikasi

Gambar 12 merupakan tampilan menu home aplikasi, berisi menu tutorial, menu simulasi soal, menu petunjuk (berisi petunjuk dari aplikasi ini), dan menu keluar untuk keluar dari aplikasi ini.

Rancang Tampilan Petunjuk Aplikasi

\begin{tabular}{|l|}
\hline $\begin{array}{l}\text { Petunjuk Penggunaan Aplikasi } \\
\text { Rambu-Rambu Lalu Lintas }\end{array}$ \\
Keterangan: \\
1. Aplikasi ini berisi tentang \\
xxxxxxxxxx \\
2. Aplikasi ini juga berisi simulasi \\
xxxxxx \\
3. Pada aplikasi ini akan \\
memberikan xxxx \\
Kembali
\end{tabular}

Gambar 13 Rancangan Petunjuk Aplikasi
Gambar 13 merupakan tampilan petunjuk aplikasi, berisi tentang informasi kegunaan dari aplikasi ini, mulai dari tentang pembelajaran rambu-rambu lalu lintas sampai dengan simulasi soal tentang ramburambu lalu lintas serta rekomendasi untuk mempelajari kategori tertentu dalam ramburambu lalu lintas.

\section{c. Rancang Tampilan Tutorial Rambu}

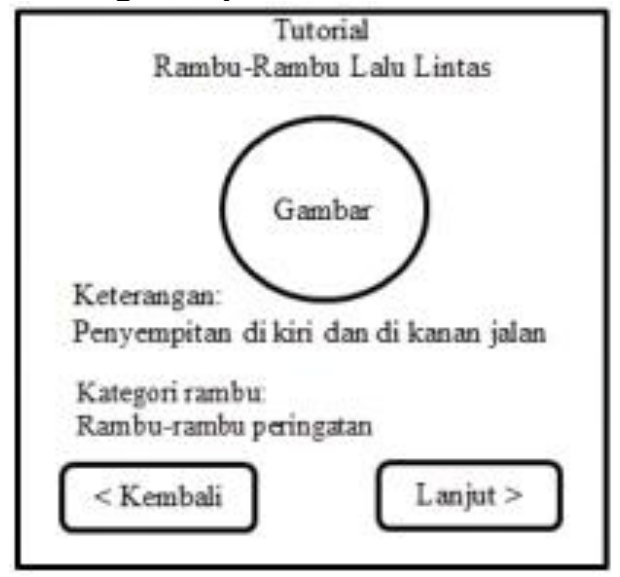

Gambar 14 Rancangan Tutorial Rambu

Gambar 14 merupakan tampilan tutorial rambu peringatan, yang berisi gambar dari rambu, keterangan dari rambu dan kategori dari rambu tersebut.

d. Rancangan Simulasi Soal

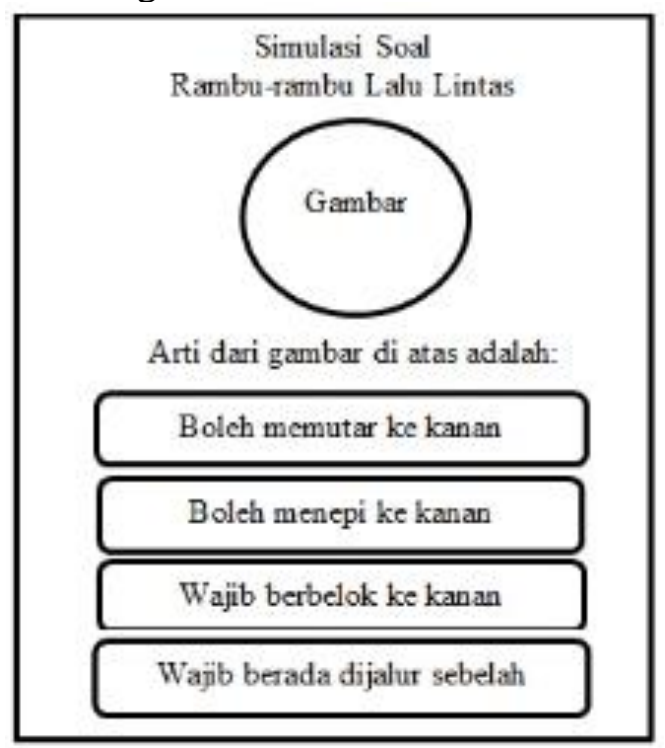

Gambar 15 Rancangan Simulasi Soal 
Gambar 15 merupakan tampilan simulasi soal yang berisi tentang gambar rambu dengan beberapa pilihan jawabandari soal gambar rambu tersebut.

\section{e. Rancangan Hasil Simulasi Soal}

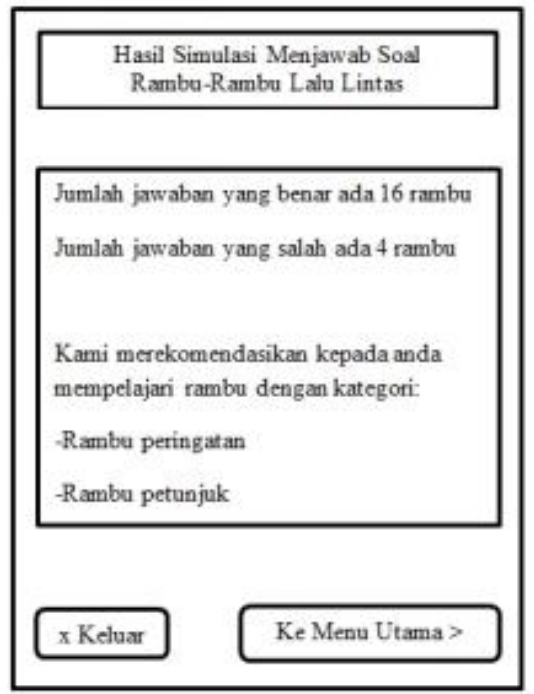

Gambar 16 Rancangan Hasil Simulasi Soal

Gambar 16 merupakan tampilan hasil simulasi yang berisi informasi berapa banyak jumlah benar dan salah serta merekomendasikan untuk mempelajari kategori rambu yang belum dikuasai.

\section{Implementasi Aplikasi}

Berikut ini adalah implementasi dari aplikasi yang dibuat oleh penulis, yaitu:

a. Tampilan Awal

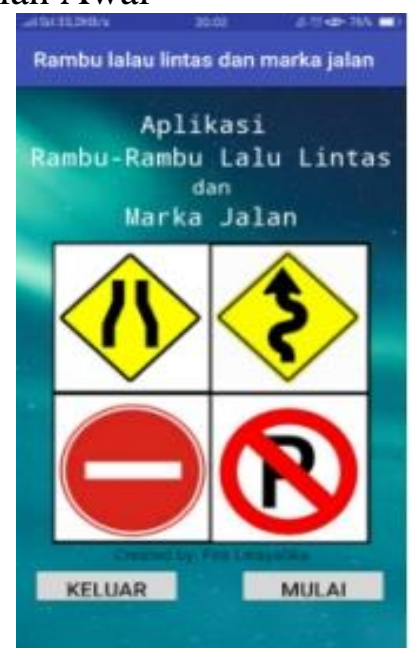

Gambar 17 Tampilan Awal b. Menu Home

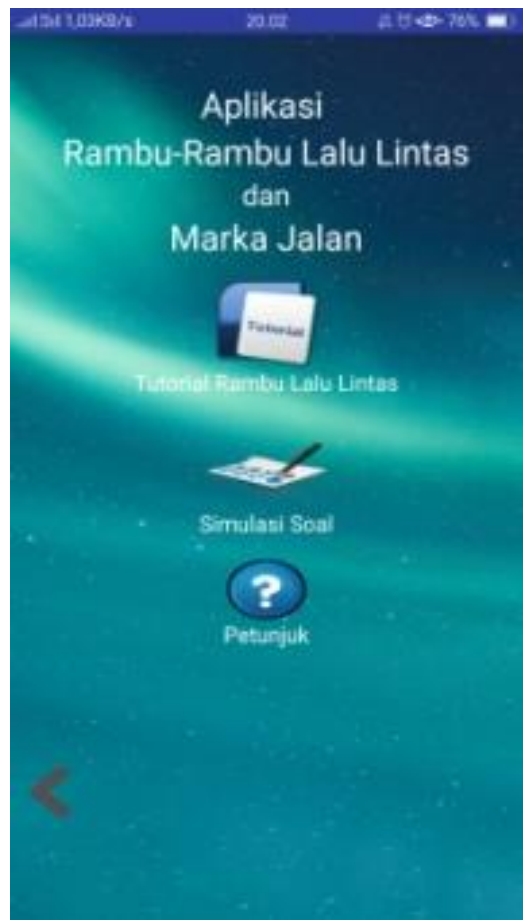

Gambar 18 Menu Home

c. Menu Tutorial

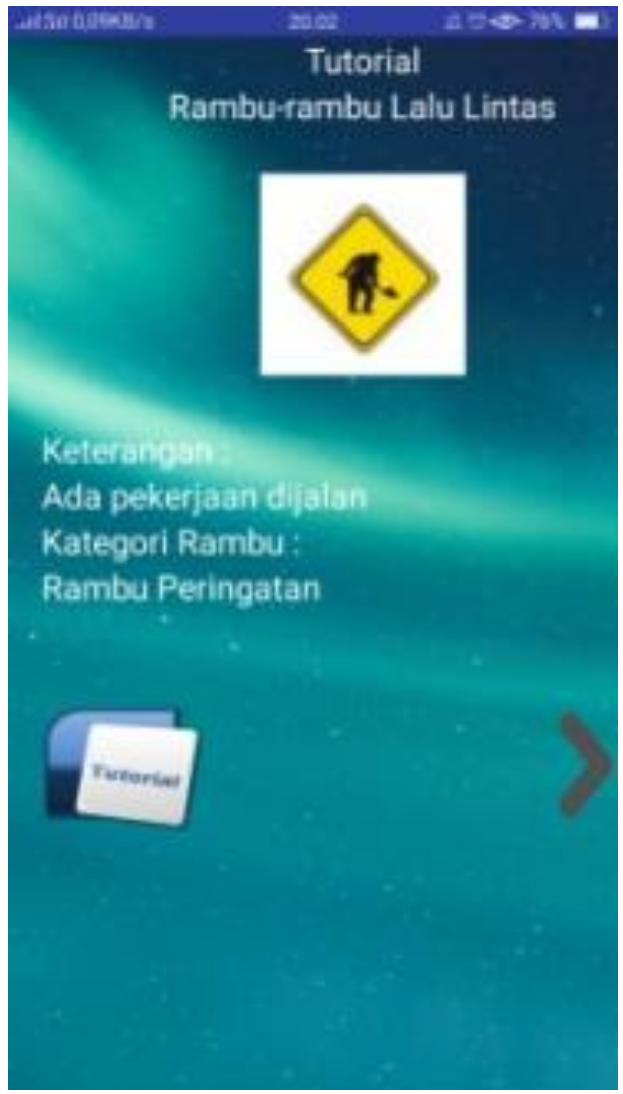

Gambar 19 Menu Tutorial 


\section{d. Menu Simulasi Soal}

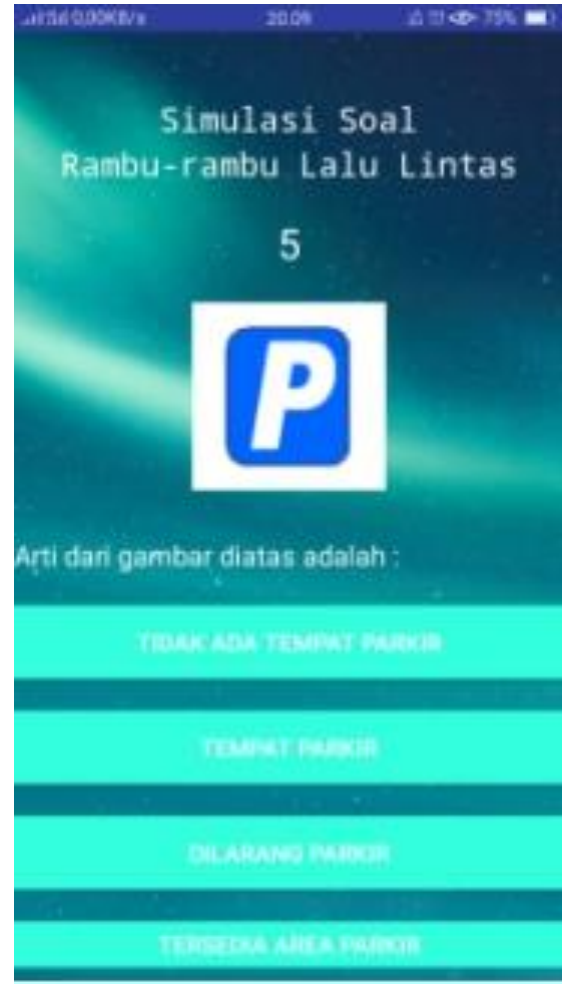

Gambar 20 Menu Simulasi Soal

\section{Kesimpulan Dan Saran}

\section{Kesimpulan}

Berdasarkan penelitian dan analisa dari peneliti yang telah dipaparkan pada bab-bab sebelumnya, maka dapat ditarik kesimpulan seperti berikut ini:

a. Untuk menciptakan masyarakat yang sadar berlalu lintas maka perlu diadakan edukasi tentang berlalu lintas, salah satunya diberikan pengajaran tentang rambu-rambu lalu lintas dan marka jalan. Dengan adanya pemahaman tentang rambu-rambu lalu lintas dan marka jalan dapat meminimalisasi terjadinya pelanggaran berlalu lintas.

b. Aplikasi pembelajaran rambu-rambu lalu lintas dan marka jalan yang paling efektif adalah berupa aplikasi berbasis mobile android. Untuk membuat aplikasi ini dapat menggunakan Android Studio yang selalu disupport oleh Google.

c. Untuk mengukur pemahaman terhadap rambu-rambu lalu lintas dan marka jalan, pada aplikasi yang dibuat oleh penulis adalah memberikan simulasi soal rambu-rambu lalu lintas dan marka jalan. Hasil dari pengerjaan simulasi soal ini nanti akan diinformasikan jumlah benar dan salahnya serta menampilkan rekomendasi untuk mempelajari kategori rambu tertentu.

\section{Saran}

Berdasarkan hasil penelitian yang dilakukan oleh peneliti, maka Penulis memberikan saransaran sebagai berikut ini:

a. Selalu melakukan review terhadap aplikasi yang Penulis buat ini, apabila ada yang dirasa masih kurang sempurna dapat dikembangkan dan disempurnakan lagi.

b. Aplikasi ini dapat dikembangkan lebih baik lagi menjadi alat tes pada pengajuan pembuatan SIM di kepolisian dalam hal pemahaman rambu-rambu lalu lintas dan marka jalan.

\section{Daftar Pustaka}

Arifianto Teguh.2011. Membuat Interface Aplikasi Android Lebih Keren dengan LWUIT. Yogyakarta: Andi.

Periangan, Benardo. 2011. Perancangan Media Interaktif Belajar Mengenal angka Bagi Anak Prasekolah. Bandung: Universitas Komputer Indonesia

Darmawan, D. 2011. Teknologi Pembelajaran. Bandung: Remaja Rosdakarya.

Edy Winarno, Ali Zaki, SmithDev.2014. Pemrograman Web Berbasis HTML5, PHP, dan JavaScript. Jakarta: PT Elex Media Komputindo.

Hendrayudi.2011. Dasar-dasar Pemrograman Microsoft Visual Basic 2008.Bandung: Satu Nusa.

Hermawan S, Stephanus. 2011. Mudah Membuat Aplikasi Android. Yogyakarta: Andi Offset.

Kustiyahningsih.2011. Pemrograman Basis Data Berbasis Web Menggunakan PHP \& MySql. Yogyakarta: Graha Ilmu

Nugroho, Adi. 2010.Rekayasa Perangkat Lunak Berbasis Objek dengan Metode USDP. Yogjakarta: Penerbit Andi 
Periangan, Benardo.2011. Perancangan Media Interaktif Belajar Mengenal angka Bagi Anak Prasekolah. Bandung: Universitas Komputer Indonesia

Rosa. A.S., dan Shalahuddin. M .2014. Rekayasa Perangkat Lunak. Cetakan ke-2. Bandung: Informatika.

Safaat, Nazaruddin H.2015.Aplikasi berbasis Android "Berbagi implementasi dan pengembangan aplikasi mobile aplikasi mobie berbasis android", Edisi Revisi. Bandung: Informatika

Safaat, Nazaruddin H.2011.Pemrograman Aplikasi mobile smartphone dan tablet PC berbasis Android. Bandung: Informatika.

Sutabri, Tata.2011. Konsep Sistem Informasi.Edisi I. Yogyakarta: Andi

Zaki, Ali dan Smitdev Community. 2011. Trik Mengamankan Komputer untuk Pemula.edisi kedua. Jakarta : Elex Media Komputindo. 